\title{
Characterizing teacher-asked questions in a high school physics classroom
}

\author{
Brianna Santangelo, and AJ Richards \\ Physics Department, The College of New Jersey, 2000 Pennington Rd., Ewing, NJ 08628
}

\begin{abstract}
One of teachers' greatest tools in the classroom is questioning. It has long been theorized that higher-level questioning leads to students developing a better understanding of the material but no one has examined the types of questions asked in physics classrooms in great detail. We used Bloom's revised taxonomy to classify the questions asked by a high school physics instructor and surveyed him on what he believes his questioning patterns to be. By analyzing the distribution of question types and the teacher's self-perceived questioning patterns we take a first step to better understanding the use of questioning in physics classrooms.
\end{abstract}

\section{INTRODUCTION AND MOTIVATION}

Education researchers have investigated the link between the use of questions in the classroom and students' understanding of content for decades. This research largely argues that high level questioning leads to better understanding for students [1-3]. However, researchers are just starting to look at the actual questioning patterns in classrooms within specific disciplines. In regards to physics, there has been little research on what types of questions are being asked in high school physics classrooms.

In a recent study, researchers have examined the use of open vs. closed questions and scientific vs. non-scientific questions in one physics and one chemistry classroom in separate Portuguese secondary schools [4]. Each classroom was voice-recorded for 45 minutes, the recordings were then transcribed and analyzed, and both teachers were interviewed about their questioning. They found that all questions asked during their observations in each classroom were closed questions, or "one right answer" questions, and that $31 \%$ of teacher-asked questions were not content-related. These findings agree with previous results that the majority of questions asked in classrooms are lower level questions or related to classroom management $[1,5]$. They also found that both science teachers were surprised by the number and kind of questions they were asking in the classroom. In other studies focusing on disciplines related to physics, such as computer science [6], most academic questions fell into the bottom three levels of Bloom's taxonomy - Knowledge or Remembering, Comprehension or Understanding, and Application or Applying [7].

Overall, while it has been theorized that the use of higherlevel questions leads to better understanding [1-3], it appears the majority of questions asked in classrooms do not meet this standard. Can this be said about physics high school classrooms in particular? While current research results imply physics teachers are asking closed questions and are unaware of their questioning patterns, they do not comment on the level of questions asked. This study takes a closer look at questioning patterns in a high school physics classroom in particular and seeks to understand in detail (1) what kinds of questions are being asked in the classroom and (2) how aware the physics teacher we studied is of his questioning.

\section{METHODS}

To examine the questioning patterns in the classroom, we video-taped five nonconsecutive physics lessons in one course of approximately 25 students in a "Physics First" suburban high school in the Northeastern United States (in "Physics First" programs, physics is taught to $9^{\text {th }}$ graders rather than to $11^{\text {th }}$ or $12^{\text {th }}$ graders; this implies that the mathematical sophistication of the students is at the pre-algebra or algebra level.) The recording started when students had finished Newton's first law and were moving on to how forces affect an object's motion. The recording finished after the students learned Newton's third law and were reviewing all three laws. The camera focused on our teacher during these lessons both when he was addressing the entire class and interacting with students in small groups or one-on-one. We then transcribed the videos and coded each question in the transcript.

The teacher we observed serves as an adjunct at our institution and volunteered to participate in this study. He uses modern, research-based pedagogical methods and he is considered an effective instructor by both his peers and the administration at his school. There was also a one-on-one aide in the classroom who assisted a student with a disability but was not involved in teaching any content to the students. The majority of the class time recorded was spent either having class-wide discussions about problems and previous labs or having students work in groups either on labs or problems. We chose to record lessons pertaining to Newton's laws and forces because one of the long term goals of this project is to examine how teacher questioning patterns affect student understanding of Newtonian mechanics.

We chose to use a combination of several coding systems for the teacher-asked questions in our classroom. First, we coded each question as an academic (content related) question or as a Procedural (non-content related) question. We then coded every academic question as a closed (one correct answer) question or open (multiple correct answers) question. Finally, we used Bloom's revised taxonomy [8] as an additional coding system for academic questions. The levels for the academic questions are: Remembering (factual recall questions that only require rote memorization), Understanding (questions involving explaining concepts and being 
TABLE I. Examples of questions at each classification level from the data set.

\begin{tabular}{ll}
\hline \hline Level & Definition \\
\hline Procedural & $\begin{array}{l}\text { This level is for any non-academic questions. This could in- } \\
\text { clude classroom management questions, clarification questions, } \\
\text { or general questions. } \\
\text { This level is for factual recall questions that need information } \\
\text { retrieval with no interpretation or inference. }\end{array}$ \\
Understanding & $\begin{array}{l}\text { This level is for questions that involve explaining concepts, us- } \\
\text { ing concepts in familiar situations, interpreting and/or summa- } \\
\text { rizing information, and drawing inferences. }\end{array}$
\end{tabular}

Applying

This level is for questions that requires students to implement their knowledge, information, and concepts in a novel setting or scenario.

Examples from data

"Can we reconvene everyone?"

"So, what you are saying is...?"

"You brought Cheez-its?"

"The $\cos (90)$ is...?"

"What's the third law again?"

"What interacts with the iPad as it falls?"

"When we think about friction what are we talking about? What objects are there?"

"What if the force pushing the object was the same but the particles were resisting more? What would happen?"

"So, if we had repeated this process on the ice do you think I would have accelerated more, less, or the same given the same force?"

Analyzing

This level is for questions that ask students to assess situations, break information into parts, and recognize patterns or trends.

"Can we connect this to our experiment with the bowling ball?"

"When we think about situations like this, what are some issues that we should think about?"

Evaluating

This level is for questions that ask students to compare theories, assess outcomes, and make judgments.

There were no examples of this level in our data set.

This level is for questions that ask students to use old concepts to create something new.

"People make this claim that the vertical tension is the same as this diagonal tension. How could you prove it?"

able to use concepts in familiar situations), Applying (questions that require students to apply information and concepts to new situations), Analyzing (questions that ask students to assess situations and recognize patterns or trends), Evaluating (questions that ask students to compare theories, assess outcome, and make judgments), and Creating (questions that ask students to use old concepts to create something new) (see more detailed definitions in Table I). Using this coding system with the addition of the Procedural level and open vs. closed categories gives additional granularity that previous studies [4] have lacked while also accounting for the noncontent related questions that many studies $[4,9]$ have shown make up a significant portion of the questions in classrooms.

The majority of questions were looked at as individual questions except when one question could not be understood without the previous one. An example of this is when our instructor asked, "Alice ${ }^{1}$, is she right? [Alice nods] Comment?". In this example, the teacher is asking the student if an answer given by another student is correct. When Al-

\footnotetext{
${ }^{1}$ All student names have been changed.
}

ice only nodded their head in response our teacher asked her to follow up with an explanation. The "Comment?" part of the question cannot be analyzed without the first question. In cases like this, we treated the second question as part of the first.

To ensure the code's reliability, the two authors and an undergraduate assistant coded two excerpts of the transcripts (about $30 \%$ of the total data set) separately then came together to discuss codes and decide on a final system. For the first excerpt, we had $93 \%$ agreement after discussion. We then transcribed the other excerpt separately and came together to discuss again as an additional reliability check. This time we had an agreement of $94 \%$ after discussion. Each coder then coded a portion of the remaining data independently.

In total, the authors disagreed on the coding of three out of the 491 questions. Two of these questions asked the students to think about jumping on a bed vs. standing on a bed. The first author thought the teacher was simply asking the students to retrieve information (a Remembering code) while the second author thought he was asking the students to consider the situation and infer what would happen (an Understanding code). The third question asked the students what a signifi- 
TABLE II. Table of results. Note that Open vs Closed and Bloom's taxonomy level are only coded for Academic questions.

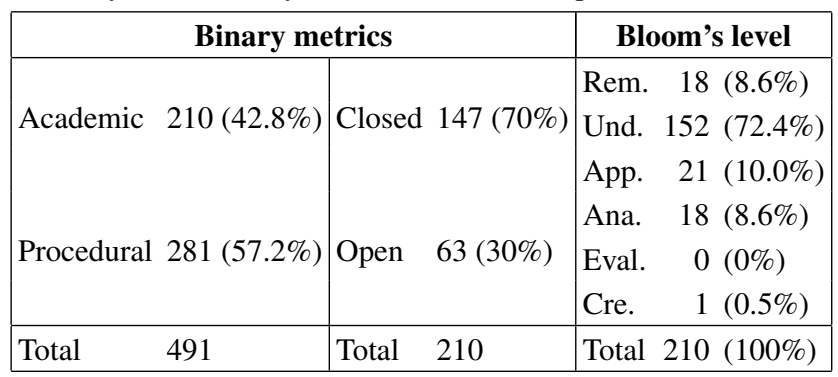

cant digit was and a similar disagreement occurred.

After recording the data, we asked our teacher to complete a survey that asked him to reflect on and describe his questioning patterns. This survey included: how he used questioning in the classroom, how many questions he asked during a typical 40 minute lesson, how many open vs. closed questions he asked, and how many factual recall vs. higher level (Analyzing, Evaluating, Creating) questions he asked. We used this survey to gain insight into why our teacher used questioning as he did and to compare his self-perceived questioning patterns to what we measured during his lessons.

\section{RESULTS}

In total, we recorded six and a half hours of class time and coded 491 questions. Of these questions, 57.2\% were Procedural questions. Of the 210 content-related questions, 18 (8.6\%) were coded as Remembering, 152 (72.4\%) as Understanding, $21(10.0 \%)$ as Applying, 18 (8.6\%) as Analyzing, 0 $(0 \%)$ as Evaluating, and $1(0.5 \%)$ as Creating (see examples in Table I and tabulated results in Table II).

In the survey, our teacher stated that he asked 18 to 36 questions every 40 minutes of class time. He estimated that about $33 \%$ of his questions were closed (one correct answer) questions but also said that "perhaps the percentage of closed questions is higher than I think." This correlates well with the purpose of questioning described by our teacher in the survey. He described five different purposes to questions in his classroom: designing a lab, defending reasoning, probing for consistency in thinking, either asking students to repeat themselves or rephrasing a student's idea, and "what-if" questions. Out of the five purposes he noted in the survey, only the "what-if" questions, in which he would change a single variable of a problem and ask the students what would happen, are usually closed questions. He also estimated about $25 \%$ of his questions could be answered through factual recall alone stating that he was "probably low on the percentage of factual recall questions.”

In the transcripts, we found he asked an average of 21.5 questions per 40 minutes which falls within the range specified by our teacher. However, we also found that $70 \%$ of his questions were closed questions and $8.6 \%$ of his questions could be answered through factual recall alone. Interestingly, our teacher's comments about how high his closed question percentage is and how low his factual recall question percentage is were accurate while his estimated percentages were not. This comparison leads us to believe that our teacher is generally aware of his questioning pattern even though he did not estimate the fraction of his questions that were closed or factual recall questions accurately.

\section{DISCUSSION}

We found that the vast majority of academic questions were at the Understanding level. While it is encouraging that there were very few Remembering questions (implying that almost all the questions required some reasoning beyond factual recall or regurgitation), less than $20 \%$ of the questions were above the Understanding level. Several researchers have argued that it is the higher level questions that help students understand the content they are learning [1-3] so we would hope to see these questions in the classroom. We would like to remind the reader that the teacher we observed is considered an effective instructor. If even an experienced physics teacher of his caliber struggles to ask a wide variety of higher-order questions, this may indicate a shortcoming in physics teacher preparation programs. Teachers are trained to ask questions that require reasoning to answer rather than simply recalling facts, and indeed our subject did accomplish that. However, the relative absence of many higher-level questions may imply that physics education programs need to do a better job helping teachers recognize how to engage students effectively at all levels of Bloom's taxonomy.

We also note that our teacher was acutely aware of certain aspects of his questioning pattern and yet unaware of other aspects. Unlike participants in previous studies [1, 4, 9], our teacher was aware of how many questions he asked in a typical lesson. He also asked more Procedural questions than these participants. We believe this may be due to how he uses questioning in the classroom. In the survey, he describes how he will often rephrase a student's statement as a question to ensure that he understands what the student is saying and to give other students additional time to think about the topic at hand and what the first student said (e.g, "So, what you're telling me is [rephrasing of student's previous response]?"). We observed this technique multiple times every session and in our coding scheme this is considered a Procedural question. This could explain why our teacher had a larger percentage of Procedural questions than other teachers were previously observed to use.

Our teacher inaccurately estimated the fraction of his questions that were closed questions and factual recall questions. He underestimated his use of closed questions and overestimated his use of recall questions. We believe there could be two explanations for this. The first is that our teacher is genuinely less aware of these aspects of his questioning patterns. 
This was common in participants of other studies [1, 4, 9] with multiple subjects being less aware of their questioning patterns than our teacher. The second is that our teacher may be unaware of what constitutes a closed or factual recall question and is mislabeling them. Thus, he may be aware of his questioning patterns but simply mislabeled them according to our coding scheme.

\section{LIMITATIONS AND FUTURE WORK}

Due to the small sample size of this work, our results may not necessarily be generalizable to other classrooms and populations. Also, our classroom was part of a "Physics First" program which could certainly influence our teacher's questioning patterns due to the age, experience level, and mathematical sophistication of the students. We hope to expand the study to include a significantly larger number of classrooms and instructors, in both traditional $\left(11^{\text {th }}\right.$ and/or $12^{\text {th }}$ grade classrooms) and "Physics First" settings. Future research could focus on the similarities and differences between questioning in "Physics First" and traditional physics classrooms, surveying more physics teachers about their questioning strategies, and examining how questioning techniques can be most effectively taught in physics teacher education programs.

[1] M.D. Gall, Educational Leadership, 42 40-47 (1984).

[2] T. Andre, Review of Educational Research, 49 280-318 (1979).

[3] D. Redfield and E. Roussea, Review of Educational Research, 51 237-245 (1981).

[4] P. Almeida and F. N. Souza, Int. J. Learning and Change, 4(3) 237-251 (2010).

[5] R. Marzano, D. Pickering, and J. Pollock, Classroom Instruction that Works: Research-based Strategies for Increased Stu-

\section{SUMMARY}

We examined how a high school physics teacher uses questioning in his classroom. We found that our teacher follows similar patterns seen in previous studies in other content areas, such as having a large amount of Procedural or classroom management questions, but was more aware of certain aspects of his questioning patterns, such as question frequency, than previous participants in other work. Overwhelmingly, questions at the Understanding level were the most common of the academic questions; there were relatively few higher-level questions asked.

Because no one has examined questioning in high school physics classrooms in this level of detail before, this work is the first step to better understanding questioning in these classrooms. In the future, we hope to expand this study to examine a more inclusive cross-section of high school physics teachers with the goal of understanding how teacher questioning strategies impact the students' conceptual understanding.

\section{ACKNOWLEDGMENTS}

We thank Nick Bolle for his assistance in analyzing the transcript data. dent Achievement (Association for Supervision and Curriculum Development, Alexandria, 2001).

[6] C. Johnson and U. Fuller, Baltic Sea Conf. on Computing Education Research Proc. (2006).

[7] B. Bloom et. al, Taxonomy of Education Objectives, Volume 1: Cognitive Domain (Longmans, Green, New York, 1956).

[8] D. Krathwohl, Theory Into Practice, 41(4) 212-218 (2002).

[9] T. Kerry, Explaining and Questioning (Nelson Thornes Ltd., London, 2002). 